Check for updates

Cite this: Chem. Commun., 2017, 53,4140

Received 7th March 2017,

Accepted 20th March 2017

DOI: $10.1039 / c 7 c c 01750 b$

rsc.li/chemcomm

\section{Rationalizing the relative abundances of trimetallic nitride template-based endohedral metallofullerenes from aromaticity measures $\dagger$}

\author{
M. Garcia-Borràs, (D)*ab S. Osuna, (D) ${ }^{b}$ J. M. Luis $\mathbb{D}^{\mathrm{b}}$ and M. Solà (D) *b
}

\begin{abstract}
The synthesis of endohedral metallofullerenes (EMFs) from a carbon soot sample of an arc discharge leads to a variety of EMFs that are obtained in different relative abundances. In the present work, we show that these abundances can be predicted from aromaticity calculations. In particular, we use the normalized Additive Local Aromaticity $\left(A L A_{N}\right)$ index. Our results show that the most abundant $\mathrm{Sc}_{3} \mathrm{~N}$-based and $\mathrm{Y}_{3} \mathrm{~N}$-based EMFs in fullerene soot are the most aromatic. This study reinforces the idea that aromaticity plays a key role in determining the stability of EMFs.
\end{abstract}

Endohedral metallofullerenes (EMFs) have attracted much attention since their discovery because of their extraordinary properties and potential applications. ${ }^{1-3}$ Many different EMFs are obtained by arc discharge or laser vaporization, but only a few of them are produced in macroscopic amounts. The first endohedral metallofullerene obtained in macroscopic quantities was the $\mathrm{Sc}_{3} \mathrm{~N} @ I_{\mathrm{h}}-\mathrm{C}_{80}$ trimetallic nitride template (TNT) EMF, which is the third most abundant fullerene only after $\mathrm{C}_{60}$ and $\mathrm{C}_{70}{ }^{4}$ The electronic structure of EMFs can be described by the ionic model, as proposed by Poblet and coworkers. ${ }^{5,6}$ When a metallic cluster is encapsulated inside a fullerene cage, a formal charge transfer takes place from the inner moiety to the carbon structure. In the case of TNT moieties, a formal transfer of six electrons takes place; thus its electronic structure can be described as $\mathrm{M}_{3} \mathrm{~N}^{6+} @ \mathrm{C}_{2 n}{ }^{6-}$. In 2007, Popov and Dunsch showed that hexaanionic empty fullerene isomers are good models for describing TNT EMF relative stabilities. ${ }^{7}$ Rodríguez-Fortea et al. demonstrated that the negative charge is mainly accumulated in the 5-membered rings (5-MRs) of the carbon structure, and that their distribution along the fullerene surface is crucial for stabilizing the final EMF. ${ }^{8,9}$ In 2015, Martín and coworkers

\footnotetext{
${ }^{a}$ Department of Chemistry and Biochemistry, University of California, Los Angeles, California 90095, USA. E-mail: marcgbq@gmail.com

${ }^{b}$ Institut de Quimica Computacional i Catàlisi (IQCC) and Departament de Quimica, Universitat de Girona, Campus Montilivi, 17003 Girona, Catalonia, Spain. E-mail: miquel.sola@udg.edu

$\dagger$ Electronic supplementary information (ESI) available: Description of the computational methods used, Fig. S1 with $\mathrm{Sc}_{3} \mathrm{~N} \mathrm{ALA}_{\mathrm{N}}$ analysis, and Fig. S2 and S3 with $\mathrm{Y}_{3} \mathrm{~N}$ EMF ALA $\mathrm{N}_{\mathrm{N}}$ analysis. See DOI: 10.1039/c7cc01750b
}

showed that the $\pi$-energies obtained from a Hückel molecular orbital (HMO) model are useful to predict the stability of anionic and cationic fullerene isomers. ${ }^{10}$ The authors added to the calculated HMO energies an empirical correction of strain energy due to the presence of adjacent pentagon pairs (APPs). Very recently, they demonstrated that the relative isomer stability of anionic fullerenes can be predicted by counting the numbers of three types of hexagon-based motifs and the number of APPs. ${ }^{11}$

A more stable $\pi$-electronic structure is likely to be connected with a higher aromaticity. Indeed, it is well-known that the accumulation of negative charge in the 5-MRs of EMFs increases their local and global aromatic character. ${ }^{12}$ In 2013, with the goal of understanding the chemical origin of the stability of anionic fullerene cages, we reported an extensive study showing that, for a given $\mathrm{C}_{2 n}{ }^{-m}$ cage, the most stable isomers are the ones whose total aromaticity is maximized, independently of the number of APPs they have. ${ }^{13,14}$ We formulated the maximum aromaticity criterion that gave an explanation for the isolated pentagon rule (IPR) violation in EMFs. In this study, aromaticity measurements were carried out in terms of the Additive Local Aromaticity (ALA) index. ${ }^{13,14}$ We used the HOMA geometric descriptor of aromaticity to reduce the computational cost. Still, the HOMA-based calculations provided aromaticity trends similar to those obtained with more reliable, but computationally more expensive electronic multicenter indices. ${ }^{15}$

Studies of EMF stabilities performed to date analyze the relative stability of isomers of a given $\mathrm{C}_{2 n}{ }^{-m}$ cage. Herein, we have generalized the ALA index to expand its scope and allow the direct comparison of $\mathrm{C}_{2 n}{ }^{-m}$ cages of different sizes. Our aim is to understand the differences in relative abundances in the production of EMFs by arc discharge of metal/graphite rods. To achieve this goal, we propose the normalization of the ALA index per number of rings present in the fullerene structure $\left(\mathrm{ALA}_{\mathrm{N}}\right)$. Using $\mathrm{ALA}_{\mathrm{N}}$ one can compare the aromaticities of different fullerene cages regardless of the number of carbons of the fullerene structure (see eqn (1)).

$$
\mathrm{ALA}_{\mathrm{N}}=\frac{1}{n} \sum_{i=1}^{n} A_{i}
$$




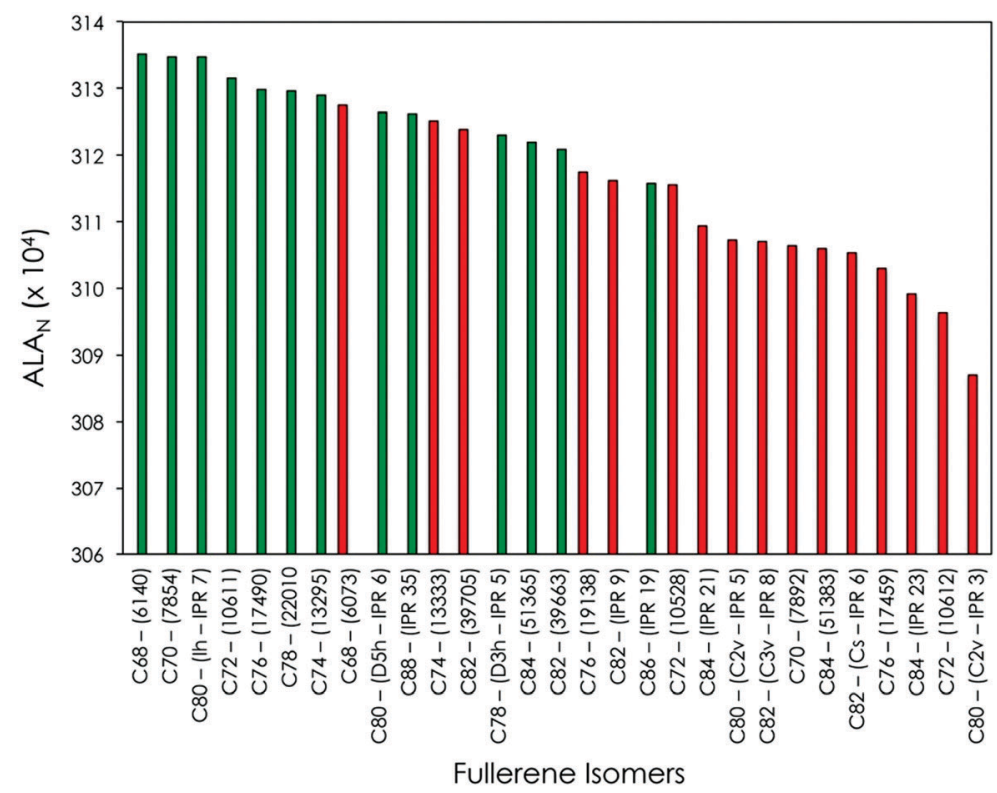

Fig. 1 Classification in terms of the $A L A_{N}$ index of selected $C_{2 n}{ }^{6-}$ fullerene isomers. The selection was made including the ALA top-ranked $C_{2 n}{ }^{6-}$ fullerene isomers for each $2 n$ (see ref. 13): isomers experimentally detected encapsulating TNTs or $M_{2}$ clusters that formally transfer 6 electrons to the fullerene structure as well as some isomers experimentally detected encapsulating $X^{4+}$ metallic clusters, such as metallic carbides. Isomers experimentally observed forming TNT EMFs are displayed in green, otherwise in red. ALA $A_{N}$ values are given in the $A L A_{N} \times 10^{4}$ format.

where $A_{i}$ is the local aromaticity of ring $i$, and $n$ is the number of rings of the fullerene structure, including both 5- and 6-MRs. In the present work, the $A_{i}$ local aromaticities in the $\mathrm{ALA}_{\mathrm{N}}$ index are computed using the accurate normalized multicenter index, $I_{\mathrm{NB}} \cdot{ }^{16} I_{\mathrm{NB}}$ allows directly comparing the aromaticities of rings with different sizes. Moreover, we assume that, when calculating the global aromaticity of the fullerene with $\mathrm{ALA}_{\mathrm{N}}$, all rings in the carbon cage have the same weight. Calculation of the $I_{\mathrm{NB}}$ electronic index ${ }^{16-18}$ for selected $\mathrm{C}_{2 n}{ }^{6-}$ isomers (see the Fig. 1 caption) was performed using the ESI-3D program ${ }^{19}$ at the B3LYP/6-31G//BP86/DZP level of theory, using the Becke's multicenter integration scheme and the topological fuzzy Voronoi $(\mathrm{TFVC})^{20}$ atomic partition scheme as implemented in the APOST-3D program ${ }^{21}$ (see the ESI $\dagger$ for complete computational details). The results obtained are summarized in Fig. 1, where the computed $\mathrm{C}_{2 n}{ }^{6-}$ fullerene isomers sorted by their $\mathrm{ALA}_{\mathrm{N}}$ values are represented. The aromaticities of the $\mathrm{C}_{2 n}{ }^{6-}$ cages are compared irrespective of their size and number of APPs.

All experimentally detected TNT-containing fullerenes exhibit the largest $\mathrm{ALA}_{\mathrm{N}}$ values (on the left in Fig. 1 and represented in green), while those hexaanionic isomers that do not form TNTbased EMFs exhibit lower $\mathrm{ALA}_{\mathrm{N}}$ values (on the right in Fig. 1 and highlighted in red). It is important to mention that, in the present analysis, we consider only the three most stable (and aromatic) isomers characterized in our previous study for each $\mathrm{C}_{2 n}{ }^{6-}$ fullerene family (see ref. 13). The rest of the possible isomers present lower $\mathrm{ALA}_{\mathrm{N}}$ values and have not been experimentally observed as TNT-based EMFs. As a general trend, experimentally observed $\mathrm{C}_{2 n}{ }^{6-}$ fullerene isomers containing TNT moieties have the largest $\mathrm{ALA}_{\mathrm{N}}$ values, thus being the most aromatic ones in terms of the $\mathrm{ALA}_{\mathrm{N}}$ index. The unique exception to this rule is the isomer $\mathrm{C}_{82}-(39705)$, which has an $\mathrm{ALA}_{\mathrm{N}}$ index slightly larger than the experimentally observed TNT isomer $\mathrm{M}_{3} \mathrm{~N} @ \mathrm{C}_{82}-(39663)$ ( $\mathrm{M}=\mathrm{Gd}$ and $\mathrm{Y})$. Nevertheless, $\mathrm{C}_{82}-(39663)$ is the second most aromatic $\mathrm{C}_{82}$ hexaanionic isomer, with an $\mathrm{ALA}_{\mathrm{N}}$ higher than all the other IPR and non-IPR $\mathrm{C}_{82}{ }^{6-}$ isomers. Our calculations also show that, among cages bigger than $\mathrm{C}_{80}, \mathrm{C}_{88^{-}}(\mathrm{IPR} 5)^{6-}$ is the most aromatic fullerene (see Fig. 1). Indeed, this is the preferred cage by more bulky 4 f-block TNTs such as $\mathrm{Ce}_{3} \mathrm{M}, \mathrm{Pr}_{3} \mathrm{~N}$ or $\mathrm{Nd}_{3} \mathrm{~N}$. We can, therefore, conclude that the most aromatic $\mathrm{C}_{2 n}{ }^{6-}(2 n=$ 68-88) fullerene cages, independently of their size or number of APPs, are those most suitable for stabilizing a TNT-based EMF. However, for large TNT moieties like $\mathrm{Ce}_{3} \mathrm{M}, \operatorname{Pr}_{3} \mathrm{~N}$ or $\mathrm{Nd}_{3} \mathrm{~N}$, predictions cannot be based only on $\mathrm{ALA}_{\mathrm{N}}$ studies because steric effects play also an important role.

Encouraged by the promising results obtained from the newly proposed $\mathrm{ALA}_{\mathrm{N}}$ index using the $\mathrm{C}_{2 n}{ }^{6-}$ model, we applied this tool for analyzing the stabilities of $\mathrm{Sc}_{3} \mathrm{~N} @ \mathrm{C}_{2 n}(2 n=68-88)$ EMFs. We computed the $\mathrm{ALA}_{\mathrm{N}}$ for $10 \mathrm{Sc}_{3} \mathrm{~N}$-based EMFs explicitly containing the scandium metallic cluster: (6140)- $\mathrm{C}_{68}$; (7854)-- $\mathrm{C}_{70}$; (2210)-- $\mathrm{C}_{78}$ (Y, Gd, Dy, Tm); ( $D_{3 \mathrm{~h}}$-IPR 5)-C $\mathrm{C}_{78}$; ( $\left.\mathrm{I}_{\mathrm{h}}-\mathrm{IPR} \quad 7\right)-\mathrm{C}_{80}$; $\left(D_{5 \mathrm{~h}}\right.$-IPR 6)-C $\mathrm{C}_{80}$; (39633)-C 82 (Y, Gd); (51365)-C $\mathrm{C}_{84}(\mathrm{Y}, \mathrm{Gd}, \mathrm{Tb})$; $\left(D_{3}\right.$-IPR 19$)-\mathrm{C}_{86}$ (Y, Gd, Tb); and ( $D_{2}$-IPR 35$)-\mathrm{C}_{88}$ (Y, Gd, Tb, $\mathrm{Lu})$. In those cases where the $\mathrm{Sc}_{3} \mathrm{~N}$-based $\mathrm{EMF}$ has not been experimentally reported, we indicate in parentheses the metals of whose TNTs have been experimentally synthesized. The equivalent $\mathrm{ALA}_{\mathrm{N}}$ analysis for $\mathrm{Y}_{3} \mathrm{~N}$-based TNT EMFs $\left(\mathrm{C}_{78}-\mathrm{C}_{88}\right)$ is reported in the ESI. $\dagger$

In Fig. 2, the relative aromaticities of scandium-based EMFs in terms of $\mathrm{ALA}_{\mathrm{N}}$ are reported. The first clear conclusion is that $\mathrm{Sc}_{3} \mathrm{~N} @ I_{\mathrm{h}}-\mathrm{C}_{80}$, the most abundant EMF, exhibits the largest normalized aromaticity. Thus, this result suggests a direct relationship between the high stability of this compound and its high aromaticity as compared to other $\mathrm{Sc}_{3} \mathrm{~N}$-based EMFs. 


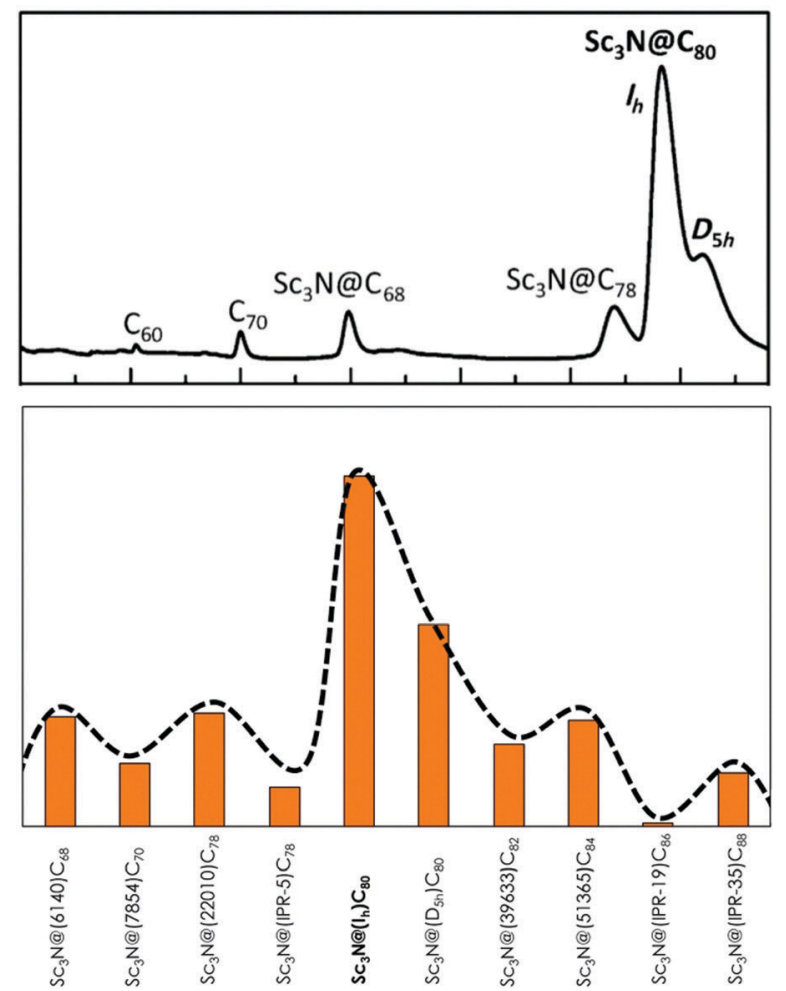

Fig. 2 Top: Quantitative HLPC chromatograms of the arc reactor carbon sample of a typical scandium based TNT EMF synthesis (adapted with permission from a previous study by Echegoyen et al., ref. 22). Bottom: Relative $\operatorname{ALA}_{N}$ scaled values $\left(\left(\operatorname{ALA} A_{N}-\operatorname{ALA}_{N}(\min )\right) /\left(\operatorname{ALA}_{N}(\max )-\operatorname{ALA}_{N}(\min )\right)\right)$, being 1 for $\mathrm{SC}_{3} \mathrm{Nal} / \mathrm{h}-\mathrm{C}_{80}$ and 0 for $\mathrm{SC}_{3} \mathrm{~N} @(I P R-19)-\mathrm{C}_{86}$, of $\mathrm{SC}_{3} N \mathrm{NCC}_{2 n}$ fullerenes, sorted by increasing cage size. See the $E S I \dagger$ for equivalent $A L A_{N}$ value graphs.

More importantly, the $\mathrm{ALA}_{\mathrm{N}}$-based aromaticity tendencies nicely reproduce the relative abundances of $\mathrm{Sc}_{3} \mathrm{~N}$ EMFs observed in the HPLC chromatogram directly obtained from a carbon soot sample of an arc discharge EMF synthesis. The second most abundant and thus presumably second most stable scandium TNT EMF is the $D_{5 \mathrm{~h}}-\mathrm{C}_{80}$. Then, $\mathrm{C}_{68}$ and $\mathrm{C}_{78}$ fullerenes are the third and fourth most abundant cages. An excellent agreement between the computed relative aromaticities and the relative abundances experimentally observed is therefore found. Our $\mathrm{ALA}_{\mathrm{N}}$ calculations, in agreement with the experimental HLPC measured relative abundances, also show that the $\mathrm{Y}_{3} \mathrm{~N} @ I_{\mathrm{h}}-\mathrm{C}_{80}$ isomer corresponds to the most abundant Y-based TNT EMFs (see Fig. S2-S4, ESI $\dagger$ ). Consequently, we propose that the aromaticity is the chemical driving force that determines the relative stability of the TNT-based EMFs, and we suggest that $\mathrm{ALA}_{\mathrm{N}}$ measures can be used to predict the relative abundances of still non-synthesized EMFs.

Minor discrepancies between experimental observations and $\mathrm{ALA}_{\mathrm{N}}$ predictions are found. For instance, the non-IPR (22010)- $\mathrm{C}_{78}$ scandium TNT EMF isomer is slightly more aromatic than the IPR $D_{3 \mathrm{~h}^{-}} \mathrm{C}_{78}$ isomer, despite the IPR is the only experimentally observed as $\mathrm{Sc}_{3} \mathrm{~N} @ \mathrm{C}_{78}$. The non-IPR isomer is, however, the preferred cage for encapsulating large metals such as yttrium or gadolinium. ${ }^{23}$ Our calculations for $\mathrm{Y}_{3} \mathrm{~N}$-based TNTs clearly show the $\mathrm{Y}_{3} \mathrm{~N}$ preference for a non-IPR (22010)- $\mathrm{C}_{78}$ cage over an IPR $D_{3 \mathrm{~h}}-\mathrm{C}_{78}$ isomer. It should be noted that our analysis does not include thermal contributions that have been shown to be necessary to explain the formation and relative abundances of a given isomer at high temperatures. ${ }^{24}$ In addition, neither kinetic or mechanistic features nor strain effects on the TNT cluster or $\mathrm{C}_{2 n}$ cage are included in our predictions. These factors could explain the minor differences between the theoretically predicted EMF ratios based on their $\mathrm{ALA}_{\mathrm{N}}$ indices and those experimentally observed in an arc discharge synthesis. Nevertheless, the experimental tendency pointing to the major formation of $\mathrm{Sc}_{3} \mathrm{~N}$-based TNTs $I_{\mathrm{h}}-\mathrm{C}_{80}$ and $D_{5 \mathrm{~h}}-\mathrm{C}_{80}$, followed by $\mathrm{C}_{68}$ and $\mathrm{C}_{78}$, is perfectly reproduced. This result indicates that aromaticity measures in terms of the $\mathrm{ALA}_{\mathrm{N}}$ index can be used not only to rationalize but also to predict the relative stability (in terms of abundance) of TNT EMFs.

In summary, we proposed a normalized Additive Local Aromaticity index as a measure for the relative stability of any hexaanionic fullerene $\mathrm{C}_{2 n}{ }^{-6}$ isomer regardless of their size (from $2 n=68$ to 88 , a typical range for TNT EMF formation), or their number of pentagon adjacencies. We have applied our new index $\left(\mathrm{ALA}_{\mathrm{N}}\right)$ to study the relative stabilities of a series of $\mathrm{Sc}_{3} \mathrm{~N}$-based EMFs. Our results show that $\mathrm{Sc}_{3} \mathrm{~N} @ I_{\mathrm{h}}-\mathrm{C}_{80}$, the most abundant EMF, is also the most aromatic, indicating that aromaticity plays a key role in determining its large stability. Even more, the good agreement between the $\mathrm{ALA}_{\mathrm{N}}$ values obtained for the $\mathrm{Sc}_{3} \mathrm{~N}$ - and $\mathrm{Y}_{3} \mathrm{~N}$-based EMF series and the experimental formation ratio indicates that this new measure can be used to understand the chemical origin of the relative stabilities of EMFs, but most importantly to predict their relative abundances.

We are grateful for financial support from the Spanish MINECO (CTQ2014-54306-P, CTQ2014-52525-P, CTQ2014-59212-P, and RyC contract to S.O.), the Catalan DIUE (2014SGR931, ICREA Academia 2014 Award to M.S. and XRQTC), and the FEDER fund (UNGI10-4E801). M.G.-B. thanks the Spanish MECD for a PhD grant (AP20102517) and the Ramón Areces Foundation for a postdoctoral fellowship. S.O. thanks the European Community for the CIG project (PCIG14-GA-2013-630978), and acknowledges the funding from the European Research Council (ERC) under the European Union's Horizon 2020 research and innovation program (ERC-2015-StG679001). CSUC and BSC-CNS are acknowledged.

\section{Notes and references}

1 H. W. Kroto, J. R. Heath, S. C. Obrien, R. F. Curl and R. E. Smalley, Nature, 1985, 318, 162-163.

2 J. R. Heath, S. C. O'Brien, Q. Zhang, Y. Liu, R. F. Curl, H. W. Kroto, F. K. Tittel and R. E. Smalley, J. Am. Chem. Soc., 1985, 107, 7779-7780.

3 A. A. Popov, S. Yang and L. Dunsch, Chem. Rev., 2013, 113, 5989-6113.

4 S. Stevenson, G. Rice, T. Glass, K. Harich, F. Cromer, M. R. Jordan, J. Craft, E. Hadju, R. Bible, M. M. Olmstead, K. Maitra, A. J. Fisher, A. L. Balch and H. C. Dorn, Nature, 1999, 401, 55-57.

5 J. M. Campanera, C. Bo, M. M. Olmstead, A. L. Balch and J. M. Poblet, J. Phys. Chem. A, 2002, 106, 12356-12364.

6 J. M. Campanera, C. Bo and J. M. Poblet, Angew. Chem., Int. Ed., 2005, 44, 7230-7233.

7 A. A. Popov and L. Dunsch, J. Am. Chem. Soc., 2007, 129, 11835-11849.

8 A. Rodríguez-Fortea, N. Alegret, A. L. Balch and J. M. Poblet, Nat. Chem., 2010, 2, 955-961.

9 A. Rodríguez-Fortea, A. L. Balch and J. M. Poblet, Chem. Soc. Rev., 2011, 40, 3551-3563. 
10 Y. Wang, S. Díaz-Tendero, M. Alcamí and F. Martín, Nat. Chem., 2015, 7, 927-934.

11 Y. Wang, S. Díaz-Tendero, F. Martín and M. Alcamí, J. Am. Chem. Soc., 2016, 138, 1551-1560.

12 J.-i. Aihara, Y. Nakagami and R. Sekine, J. Phys. Chem. A, 2015, 119, 6542-6550.

13 M. Garcia-Borràs, S. Osuna, M. Swart, J. M. Luis and M. Solà, Angew. Chem., Int. Ed., 2013, 52, 9275-9278.

14 M. Garcia-Borràs, S. Osuna, J. M. Luis, M. Swart and M. Solà, Chem. Soc. Rev., 2014, 43, 5089-5105.

15 F. Feixas, E. Matito, J. Poater and M. Solà, Chem. Soc. Rev., 2015, 44, 6434-6451.

16 J. Cioslowski, E. Matito and M. Solà, J. Phys. Chem. A, 2007, 111, 6521-6525.
17 E. Matito, M. Duran and M. Solà, J. Chem. Phys., 2005, 122, 014109. 18 E. Matito, M. Solà, P. Salvador and M. Duran, Faraday Discuss., 2007, 135, 325-345.

19 E. Matito, ESI-3D: Electron sharing indexes program for 3D molecular space partitioning, Institut de Química Computacional i Catàlisi, Universitat de Girona, Girona, 2006.

20 P. Salvador and E. Ramos-Cordoba, J. Chem. Phys., 2013, 139, 071103. 21 P. Salvador and E. Ramos-Cordoba, APOST-3D, Institut de Química Computacional i Catàlisi, Universitat de Girona, Girona, 2011.

22 M. R. Cerón, F. F. Li and L. Echegoyen, Chem. - Eur. J., 2013, 19, 7410-7415.

23 A. A. Popov, M. Krause, S. Yang, J. Wong and L. Dunsch, J. Phys. Chem. B, 2007, 111, 3363-3369.

24 M. Mulet-Gas, A. Rodríguez-Fortea, L. Echegoyen and J. M. Poblet, Inorg. Chem., 2013, 52, 1954-1959. 